\title{
Medical Image of the Week: Cardiac Magnetic Resonance Imaging Findings of Severe RV Failure
}

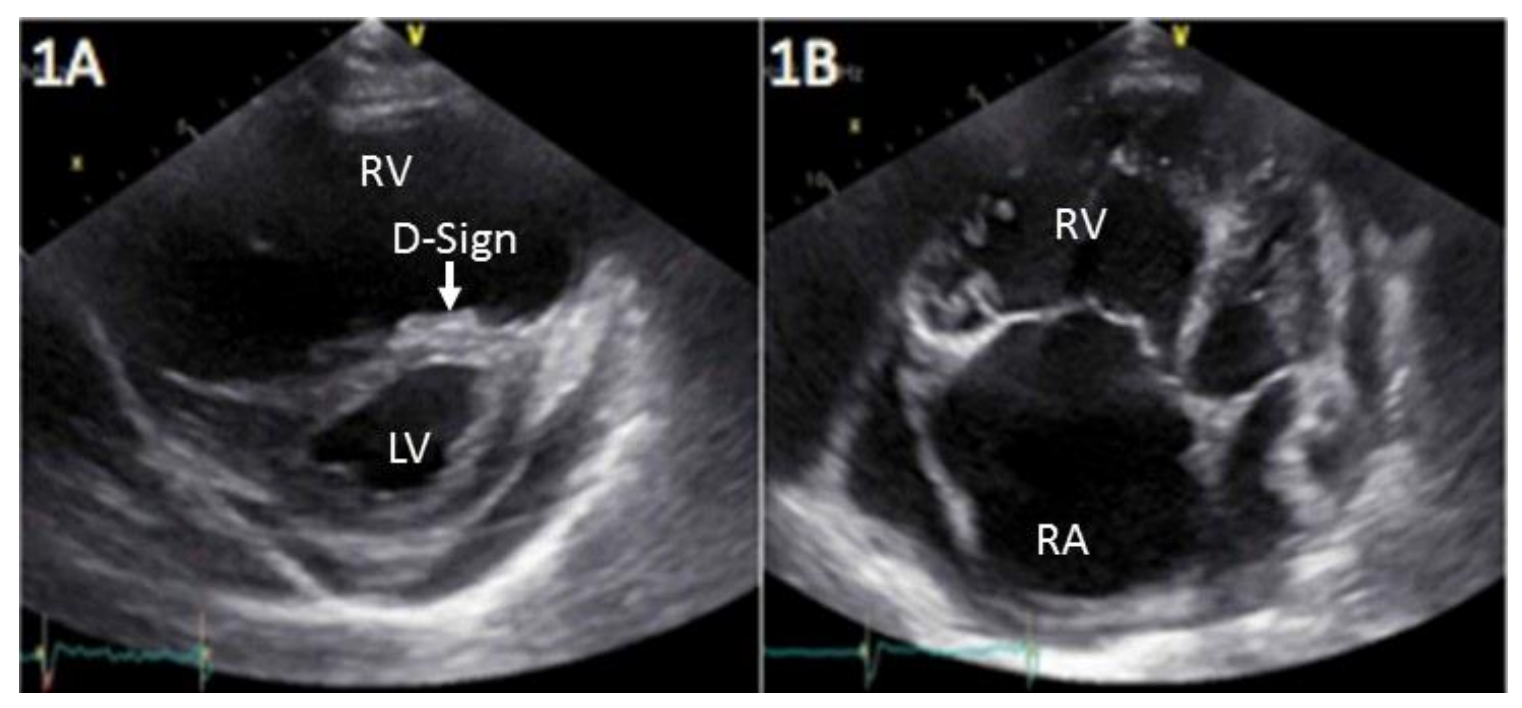

Figure 1. Transthoracic echocardiography, short-axis view (1A) and four-chamber view (1B) demonstrating leftward deviation with flattening of interventricular septum ("D-sign") due to increased right ventricular pressure and volume overload from severe pulmonary arterial hypertension $(\mathrm{PAH}) . \mathrm{RV}=$ right ventricle. $\mathrm{RA}=$ right atrium. $\mathrm{LV}=$ left ventricle.

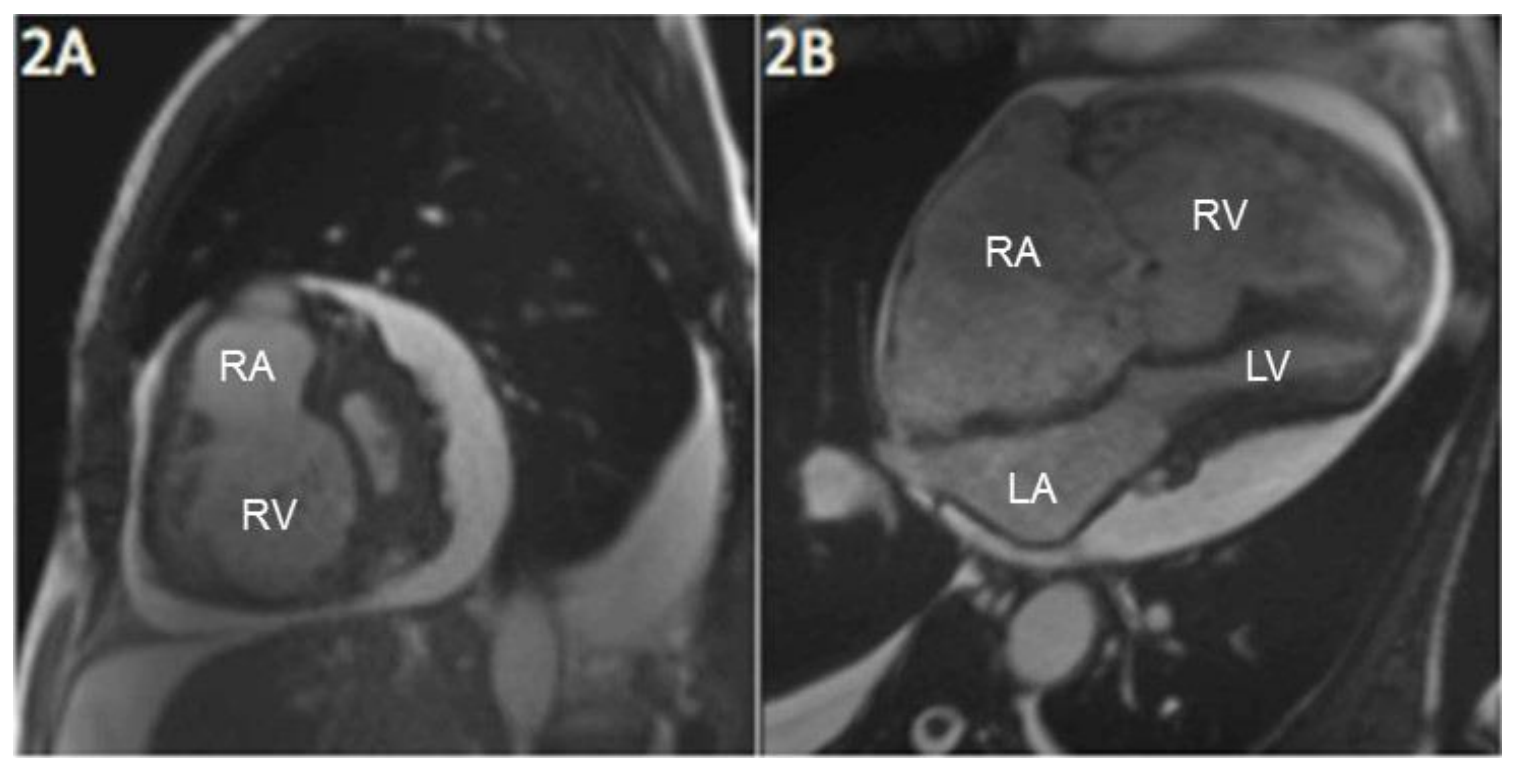

Figure 2. Cardiac Magnetic Resonance Imaging, sagittal view (2A), and cross-sectional view (2B) show the same signs of massive right ventricular $(R V)$ pressure and volume overload with severe $\mathrm{RV}$ dysfunction. RV ejection fraction of $13 \%$. RV=right ventricle. $R A=$ right atrium. $L V=$ left ventricle. $L A=l$ eft atrium. 
A 56-year-old man with history a of alcohol abuse presents with progressive shortness of breath on exertion, bilateral lower extremity swelling and 12-pound weight gain over two weeks.

His transthoracic echocardiography (Figure 1) demonstrated severely increased global right ventricle $(R V)$ size, severely dilated right atrium $(R A)$, severe pulmonary artery (PA) dilation, moderate tricuspid regurgitation (TR) and right ventricular systolic pressure (RVSP) estimated at 85 + central venous pressure (CVP) in the context of severely reduced RV systolic function. Right heart catheterization (RHC) showed PA pressure (systolic/diastolic, mean) of $94 / 28,51 \mathrm{mmHg}$ with a PA occlusion pressure of $12 \mathrm{mmHg}$. After extensive evaluation, our patient's presentation of right heart failure seemed to be a manifestation of idiopathic pulmonary arterial hypertension.

Our patient subsequently had cardiac MRI (cMRI) with findings shown above (Figure 2). $\mathrm{CMRI}$ is a valuable, three-dimensional imaging modality that provides detailed morphology of the cardiac chambers along with accurate quantification of chamber volumes, myocardial mass and transvalvular flow (1). Cardiac MRI is an accurate tool to estimate the RV function at baseline and to follow up response to treatment. RV function at presentation and after treatment are very important determinants of prognosis independent of other hemodynamic indices (2).

Kelly Wickstrom, DO ${ }^{1}$, Huthayfa Ateeli, MBBS ${ }^{2}$, Sachin Chaudhary, MD² ${ }^{1}$ Internal Medicine Department and ${ }^{2}$ Pulmonary and Critical Care Division Banner University Medical Center Tucson, AZ USA

\section{References}

1. Grünig E, Peacock AJ. Imaging the heart in pulmonary hypertension: an update. Eur Respir Rev. 2015 Dec;24(138):653-64. [CrossRef] [PubMed]

2. Swift AJ, Wild JM, Nagle SK, et al. Quantitative magnetic resonance imaging of pulmonary hypertension: a practical approach to the current state of the art. $J$ Thorac Imaging. 2014 Mar;29(2):68-79. [CrossRef] [PubMed] 